\title{
EVALUACIÓN DE ENZIMAS CELULOLÍTICAS BACTERIANAS AISLADAS DE LAS FUENTES TERMALES DE CALIENTES (CANDARAVE-TACNA)
}

\section{EVALUATION OF BACTERIAL CELLULOLIC ENZYMES ISOLATED FROM HOT TERMINAL SOURCES (CANDARAVE-TACNA)}

\author{
${ }^{1}$ Freddy Eddinson Ninaja Zegarra \\ ${ }^{2}$ Daladier Miguel Castillo Cotrina \\ ${ }^{3}$ Roberto Castellanos Cabrera
}

\section{RESUMEN}

Se recolectó muestras de agua y sedimento de ocho fuentes termales de Calientes (Candarave-Tacna). Las cuales fueron incubadas a $50^{\circ} \mathrm{C}$ por 48 horas en medio de cultivo carboximetilcelulosa (CMC). Posteriormente, se seleccionaron las cepas con mayores halos de hidrólisis y se rotularon con el código GCB-13 y GCC-13 para someterlas a tres tratamientos de temperatura: $45^{\circ} \mathrm{C}, 50^{\circ} \mathrm{C}$ y $55^{\circ} \mathrm{C}$. Las cepas GCB- 13 y GCC- 13 son bacterias Gram (+) que forman colonias blancas de 4,9 y $9,2 \mathrm{~mm}$ y cremas de 2,5 y $10,3 \mathrm{~mm}$ respectivamente. La identificación molecular de cada una de estas cepas corresponde, en el mismo orden, a Bacillus sp y Paenibacillus sp. Cada 24 horas fue monitoreada la producción de proteínas totales y azúcares reductores hasta las 96 horas. Finalmente, se llegó a los siguientes resultados: Con respecto a la producción de proteínas totales de la cepa GCB-13, no se presentó diferencias significativas a $45^{\circ} \mathrm{C}, 50^{\circ} \mathrm{C}$ y $55^{\circ} \mathrm{C}$; caso contrario a la producción de azúcares reductores donde sí se determinó una mayor productividad a $45^{\circ} \mathrm{C}$ y $50^{\circ} \mathrm{C}$. Por otro lado, la cepa GCC13 no reveló diferencias significativas en la producción de proteínas totales y azúcares reductores; en consecuencia, para este caso en particular, se concluye que existe un rango más amplio de acción.

Palabras claves: Celulosa, enzimas celulolíticas, glucosa, industria, microorganismos termófilos.

\section{ABSTRACT}

Samples of water and sediment were collected from eight hot springs in Calientes (Candarave-Tacna). Which were incubated at $50^{\circ} \mathrm{C}$ for 48 hours in culture medium carboxymethylcellulose (CMC). Subsequently, strains with greater hydrolysis halos were selected and labeled with code GCB-13 and GCC-13. Each strain underwent three temperature treatments: $45^{\circ} \mathrm{C}, 50^{\circ} \mathrm{C}$ and $55^{\circ} \mathrm{C}$. Strains GCB-13 and GCC- 13 are Gram (+) bacteria that form white colonies of 4.9 and $9.2 \mathrm{~mm}$ and creams of 2.5 and $10.3 \mathrm{~mm}$ respectively. The molecular identification of each of these strains corresponds, in the same order, to Bacillus sp and Paenibacillus sp. Every 24 hours the production of total proteins and reducing sugars was monitored until 96 hours. Finally, the following results were reached: With respect to the production of total proteins of the strain GCB-13, there are no significant differences at $45^{\circ} \mathrm{C}, 50^{\circ} \mathrm{C}$ and $55^{\circ} \mathrm{C}$; in the opposite case to the production of reducing sugars where a greater productivity was determined at $45^{\circ} \mathrm{C}$ and $50^{\circ} \mathrm{C}$. On the other hand, strain GCC-13 did not reveal significant differences in the production of total proteins and reducing sugars; consequently, for this particular case, it is concluded that there is a wider range of action.

Keywords: cellulose, cellulolytic enzymes, glucose, industry, thermophilic microorganisms. 


\section{INTRODUCCIÓN}

\section{Antecedentes}

La pared celular vegetal secuestra cantidades significativas de polisacáridos metabólicamente inactivos de entre las siguientes clases: celulosas, hemi-celulosas, lignina (Thomson, 1993). Las cadenas de celulosa están formadas por monómeros de glucosa unidos por $\beta$ - $(1,4)$ glucano y además pueden contener hasta varios cientos de polímeros celulósicos (Beguin y Aubert, 1994; Mejia- Castillo et al., 2002). La celulosa es degradada mediante la acción de varias enzimas no asociadas en complejos o formando un complejo denominado "celulosoma" (Murashima et al., 2002; Lynd et al., 2002). Dichas enzimas han sido ampliamente estudiadas en hongos mesófilos, tales como Trichoderma reesei (Lynd et al., 2002). Sus actividades hidrolíticas son afectadas por una serie de factores físicos y químicos, como $\mathrm{pH}$ extremos, solventes orgánicos, detergentes iónicos y elevadas temperaturas. Martínez et al. (2005), Pérez et al. (2002) y Hernández-Santoyo et al., (1999) coinciden en señalar que la celulosa es una de las moléculas poliméricas más abundantes en la biósfera, que se degrada naturalmente por sistemas enzimáticos conformados por endo $\beta 1-4$ glucanasas, exo $\beta 1-4$ glucanasas y $\beta$ glicosidasas; los mismos que-de acuerdo con Maki et al. (2011), Yin et al. (2010), Cuervo et al. (2009), Sheble et al. (2007), Atlas y Bartha, (2005), Terry-Brown et al. (2004), Pérez et al. (2002), Mejía- Castillo et al. (2002), HernándezSantoyo et al. (1999), Hreggvidsson et al. (1996) y Viviano et al. (2011) - transforman de manera sinergística el polímero en D-glucosa. Se puede encontrar tres tipos de actividad enzimática: Exoglucanasas, que hidrolizan los enlaces glucosídicos terminales rompiendo la estructura cristalina de la celulosa y transformándola en celulosa amorfa que libera glucosa o celobiosa (García et al., 2003). Endoglucanasas, cuya acción se da en las porciones amorfas de las fibras de celulosa donde rompen los enlaces $\beta-1,4$ glucosídicos y generan oligosacáridos de distintas longitudes, lo cual implica la formación de nuevos extremos reductores y no reductores (Rodríguez, 2005). $\boldsymbol{\beta}$-Glucosidasa, esta enzima hidroliza los monómeros de glucosa, y resulta sumamente importante para que se produzca la degradación completa de la celulosa (García et al, 2003). Las celulasas tienen un uso industrial muy amplio; particularmente en los procesos para fabricar textiles, cueros y papel donde se requiere enzimas que funcionen a temperaturas y $\mathrm{pH}$ extremos (Liang et al., 2009; Liang et al., 2010; Ovando et al., 2005). Asimismo, puede aplicarse en las industrias de alimentos y químicos (Sheble et al., 2007). Las celulasas constituyen un insumo importante en la fabricación de biocombustibles (Maki et al., 2011; Cuervo et al., 2009; Gómez \& Tibayde, 2009; Cruz et al., 2009; Kumar et al. 2009; Martínez-Anaya et al., 2008; Gray et al., 2006; Oliveira et al., 2006; Sissons et al., 1987) — citados, además, por Viviano et al. (2011) - En base a estos antecedentes, el presente trabajo tiene como objetivos:

1. Caracterizar macroscópica y microscópicamente a las cepas bacterianas GCC-13 y GCB-13 e identificarlas molecularmente.

2. Determinar la actividad enzimática de las celulasas producidas por las cepas GCC-13 y GCB-13, a diferentes temperaturas de incubación, y establecer la bacteria que presenta la mayor actividad de las enzimas celulolíticas producidas por dichas cepas.

\section{MATERIALES Y MÉTODOS}

\begin{abstract}
Aislamiento de las cepas bacterianas celulolíticas Se examinó ocho géiseres recolectándose, por cada uno de ellos, una muestra consistente en $350 \mathrm{~mL}$ de agua y sedimento. De cada muestra se extrajo $1 \mathrm{~mL}$ que fue colocado en $72 \mathrm{~mL}$ de caldo CMC. Este se incubó a $50^{\circ} \mathrm{C}$ por $48 \mathrm{hrs}$. El incubado se diluyó desde $10^{-1}$ hasta $10^{-5}$. Luego, se sembró cada dilución por estría en agar $\mathrm{CMC}$ a fin de ser incubados a $50^{\circ} \mathrm{C}$ por 48 horas. Posteriormente, se seleccionó colonias que presentaron un mayor halo de hidrólisis. Este procedimiento se repitió hasta obtener colonias puras. La composición de medio de cultivo CMC ( $\mathrm{g} / \mathrm{mL})$ contiene Carboximetilcelulosa 10,0; Extracto de Levadura 2,5; Peptona universal 2,5; Sulfato de amonio 0,5; Cloruro de calcio 0,5; Fosfato monobásico de potasio 0,1 ; Fosfato dibásico de potasio 0,1; Agar-agar 15,0; y pH 7 (Gaitán, 2007).
\end{abstract}

\section{Caracterización microbiológica de las cepas bacterianas celulolíticas}

Caracterización macroscópica: Esta se realizó tomando en cuenta la forma, el color, la textura y el diámetro del halo y la colonia en agar CMC, después de la incubación a $50^{\circ} \mathrm{C}$ por $48 \mathrm{hs}$.

Caracterización microscópica: Se hizo en preparados en fresco y en seco, siendo coloreadas con Gram de las colonias. Se consideró su forma y su coloración.

\section{Identificación molecular de las cepas bacterianas GCB-13 y GCC-13}

Tomando un inóculo de $10^{8} \mathrm{cel} / \mathrm{mL}$ de cada cepa, se realizó la purificación del ADN mediante el kit Wizard. El ADN obtenido se refrigeró a $-20^{\circ} \mathrm{C}$ y se trasladó vía aérea a Corea del Sur para la amplificación y secuenciamiento. Las secuencias se sometieron a las herramientas bioinformáticas de Blast server for bacterial identification de la base de datos de National Center for Biotechnology and Information (NCBI).

\section{Producción de enzimas celulolíticas}

Para cada cepa se preparó 9 frascos de $100 \mathrm{~mL}$, y en cada uno de ellos fue agregado $70 \mathrm{~mL}$ de caldo $\mathrm{CMC}$ 
con $1 \%$ de carboximetilcelulosa y $10 \%$ de inóculo microbiano con la concentración de $10^{8} \mathrm{cel} / \mathrm{mL}$. Los frascos finalmente se incubaron durante 96 horas a 45, 50 y $55^{\circ} \mathrm{C}$, y se airearon con 0,6 VVM. Para realizar las evaluaciones se tomó muestras de los frascos en incubación a las 24, 48, 72 y 96 horas de iniciada la experimentación.

- Determinación de la producción de celulasas a través de la determinación de proteínas totales por el método de Bradford

Se preparó una curva patrón con albumina sérica bovina ( $\mathrm{SAB}$ ) considerando las concentraciones de $30,60,90,120$ y $150 \mathrm{ug} / \mathrm{mL}$, sus absorbancias se determinaron a la longitud de onda de $595 \mathrm{~nm}$. Cada muestra de $1,5 \mathrm{~mL}$ fue centrifugada por 20 minutos a $4000 \mathrm{rpm}$. Se tomó $1 \mathrm{~mL}$ del sobrenadante para ser mezclado con $5 \mathrm{~mL}$ del reactivo de Bradford y se midió a $595 \mathrm{~nm}$ (Bradford, 1976).

\section{- Determinación de la actividad enzimática a través de la determinación de azúcares reductores por el método del DNS (ácido dinitrosalicílico)}

Se dispuso una curva patrón con glucosa en base a concentraciones de 250, 500, 1000, 1500 y 2000 $\mathrm{ug} / \mathrm{mL}$ cuyas respectivas absorbancias fueron determinadas en el espectrofotómetro a la longitud de onda de $540 \mathrm{~nm}$. Se centrifugó cada muestra de $1,5 \mathrm{~mL}$ por 20 minutos a $4000 \mathrm{rpm}$. Del sobrenadante, se tomó $0,25 \mathrm{~mL}$ que fue mezclado con $0,25 \mathrm{~mL}$ del reactivo DNS. Luego se llevó a baño maría hasta ebullición durante 5 minutos. Finalmente se enfrió los tubos con hielo y se le agregó $2,5 \mathrm{~mL}$ de agua destilada para medir la absorbancia a $540 \mathrm{~nm}$ (Miller, 1959).

\section{- Determinación de la producción máxima y actividad enzimática máxima de las celulasas producidas por las cepas bacterianas \\ Las concentraciones máximas de proteínas totales y de azucares reductores obtenidas para las diferentes temperaturas fueron sometidas a la prueba de ANOVA y a la prueba de Tuckey a fin de establecer la temperatura en la que hubo mayor producción de proteínas totales y, por tanto, de celulasas.}

\section{RESULTADOS}

\section{Características macroscópicas y microscópicas} de las colonias

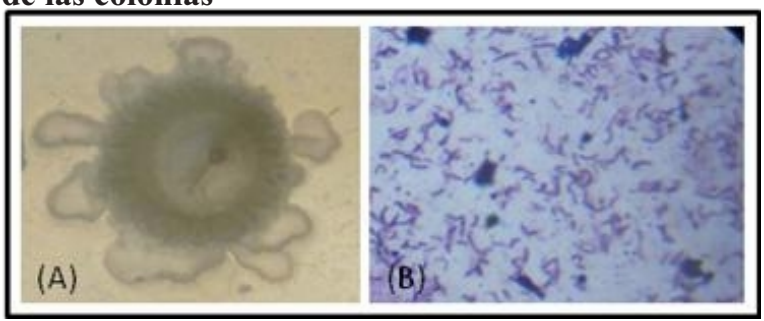

Figura 1. (A) Colonia de la cepa GCB-13 vista en el microscopio de campo claro a 100 aumentos, se aprecia en la colonia bordes lobulados poco definidos con una zona central más densa y circular. (B) Bacilos Gram positivos de

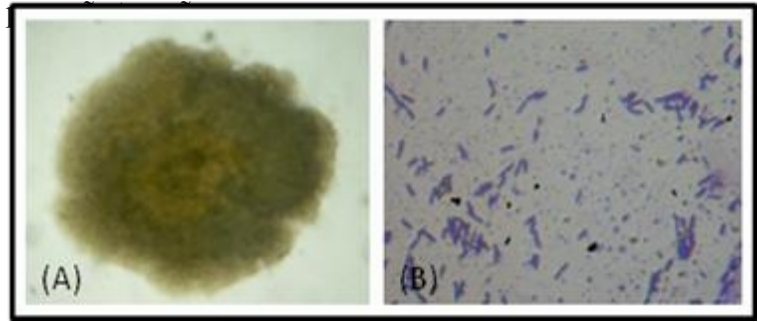

Figura 2. (A) Colonia de la cepa GCC-13 vista en el microscopio de campo claro a 100 aumentos, la colonia es densa y presenta bordes irregulares ligeramente más claros que la zona central. (B) Bacilos Gram positivos de pequeño tamaño ligeramente más anchos que la cepa GCB-13.

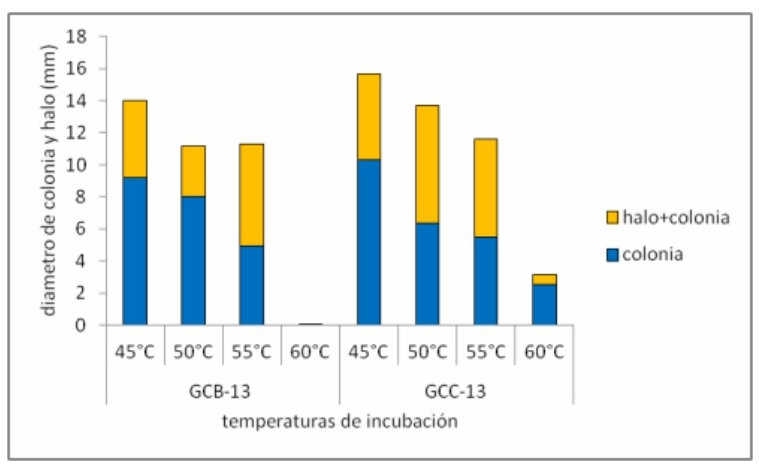

Figura 3. Diámetro de las colonias y de halos, más colonias de las cepas celulolíticas a diferentes temperaturas en agar $\mathrm{CMC}$

En la Figura 3 se muestra el diámetro de la colonia de las cepas GCB-13 y GCC-13 a las temperaturas de 45, 50 y $55^{\circ} \mathrm{C}$ donde se aprecia la producción de un mayor diámetro de colonia y de halo para ambas cepas, a la temperatura de $45^{\circ} \mathrm{C}$.

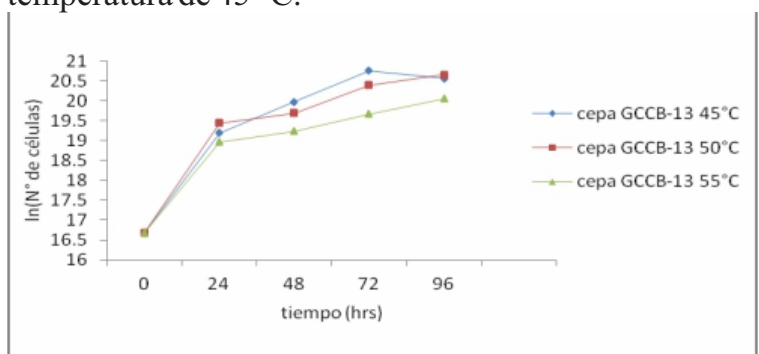

Figura 4. Curva de crecimiento de la cepa celulolítica GCB13 a 45,50 y $55^{\circ} \mathrm{C}$

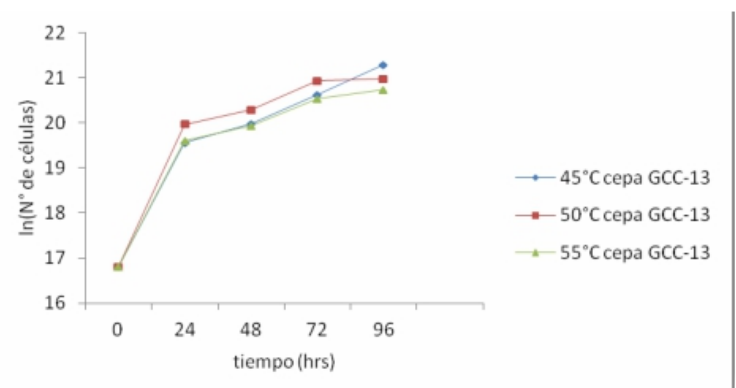

Figura 5. Curva de crecimiento de la cepa celulolítica GCC13 a 45,50 y $55^{\circ} \mathrm{C}$ 
En la Figura 4 se muestra un mayor e igual crecimiento de la cepa GCB- 13 a $45^{\circ} \mathrm{C}$ y $50^{\circ} \mathrm{C}$; así como un menor crecimiento a $55^{\circ} \mathrm{C}$. En tanto que en la Figura 5, correspondiente a la cepa GCC-13, se observa un menor e igual crecimiento a $45^{\circ} \mathrm{C}$ y $55^{\circ} \mathrm{C}$, y un mayor crecimiento a $50^{\circ} \mathrm{C}$. En los tres casos de cada cepa se da el mayor crecimiento a las 96 horas de incubación.

\section{Identificación molecular de las cepas bacterianas GCB-13 y GCC-13}

Tabla 1. Identificación molecular de las cepas microbianas GCB-13 y GCC-13 empleando las bases de datos Blast server for bacterial identification, Bacillus sp (GCB-13) y Paenibacillus sp (GCC-13)

\begin{tabular}{lll}
\hline \multicolumn{3}{l}{ Blast server for bacterial identification (NCBI) } \\
\hline Cepa & $\begin{array}{l}\text { Porcentaje } \\
\text { de identidad }\end{array}$ & Identificación \\
GCB-13 & $97 \%$ & Bacillus sp. \\
GCC-13 & $89 \%$ & Paenibacillus sp \\
\hline
\end{tabular}

Producción de celulasas a través de la determinación de proteínas totales en la cepa GCB13

Tabla 2. Proteinas totales (ug/mL) producidas por la cepa $G C B-13$ con sus tres repeticiones $(R)$ por temperatura

\begin{tabular}{llll}
\hline \multirow{2}{*}{$\begin{array}{c}\text { Repeticiones } \\
\text { del }\end{array}$} & \multicolumn{3}{c}{ Temperatura } \\
\cline { 2 - 4 } experimento & $45^{\circ} \mathrm{C}$ & $50^{\circ} \mathrm{C}$ & $55^{\circ} \mathrm{C}$ \\
\hline $\mathrm{R} 1$ & 130,54 & 87,08 & 97,08 \\
$\mathrm{R} 2$ & 121,69 & 101,3 & 93,23 \\
$\mathrm{R} 3$ & 155,15 & 117,46 & 100,92 \\
\hline Promedio & 135,79 & 101,95 & 97,08 \\
\hline
\end{tabular}

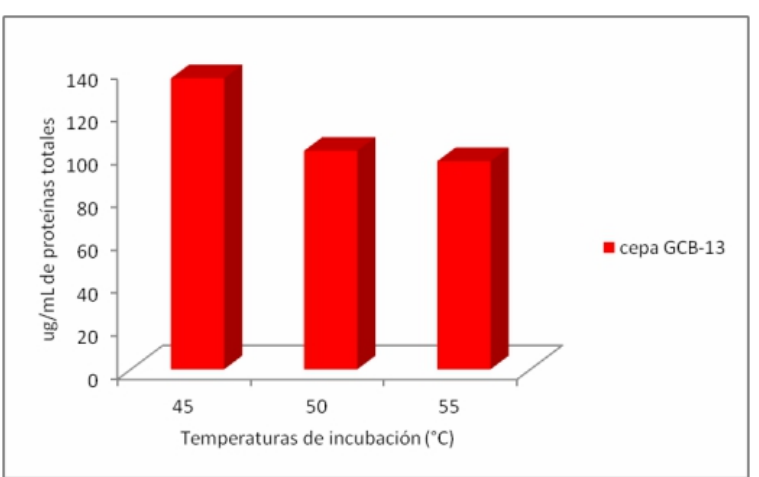

Figura 6. Proteínas totales producidas por la cepa GCB13 por temperatura
En la Tabla 2 así como en la Figura 6, se muestra mayor producción de proteínas totales a $45^{\circ} \mathrm{C}$ con un valor de $135,79 \mathrm{ug} / \mathrm{mL}$ por parte de la cepa GCB-13.

Actividad enzimática de las celulasas a través de la determinación de azúcares reductores en la cepa GCB-13.

Tabla 3. Azúcares reductores $(\mathrm{ug} / \mathrm{mL})$ producidos por la cepa $G C B-13$ en sus tres repeticiones $(R)$ por temperatura

\begin{tabular}{llll}
\hline $\begin{array}{l}\text { Repeticiones } \\
\text { del }\end{array}$ & \multicolumn{3}{c}{ Temperatura } \\
\cline { 2 - 4 } experimento & $45^{\circ} \mathrm{C}$ & $50^{\circ} \mathrm{C}$ & $55^{\circ} \mathrm{C}$ \\
\hline $\mathrm{R} 1$ & 656,67 & 386,67 & 116,67 \\
$\mathrm{R} 2$ & 666,67 & 643,33 & 196,67 \\
$\mathrm{R} 3$ & 736,67 & 543,33 & 196,67 \\
\hline Promedio & 686,67 & 524,44 & 170,00 \\
\hline
\end{tabular}

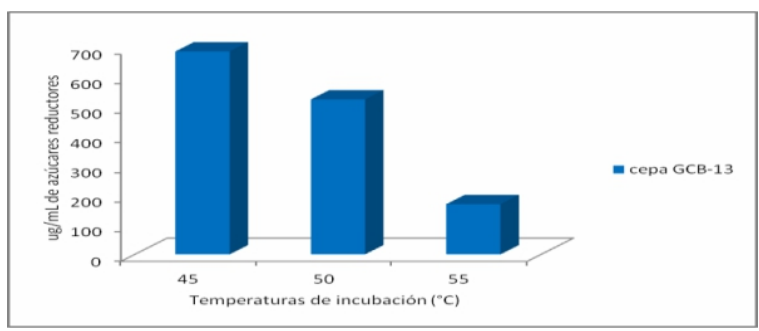

Figura 7. Representación en barras de azúcares reductores producidos por la cepa GCB-13 en sus tres repeticiones (R) por temperatura

En la Tabla 3 como en la Figura 7, se puede observar mayor producción de azúcares reductores a $45^{\circ} \mathrm{C}$ con un valor de $686,67 \mathrm{ug} / \mathrm{mL}$ por parte de la cepa GCB-13.

Producción de celulasas a través de la determinación de proteínas totales en la cepa GCC-13

Tabla 4. Proteinas totales (ug/mL) producidas por la cepa $G C C-13$ en sus tres repeticiones (R) por temperatura

\begin{tabular}{llll}
\hline \multirow{2}{*}{$\begin{array}{c}\text { Repeticiones } \\
\text { del } \\
\text { experimento }\end{array}$} & \multicolumn{3}{c}{ Temperatura } \\
\cline { 2 - 4 } & $45^{\circ} \mathrm{C}$ & $50^{\circ} \mathrm{C}$ & $55^{\circ} \mathrm{C}$ \\
\hline $\mathrm{R} 1$ & 241,31 & 178,62 & 102,46 \\
$\mathrm{R} 2$ & 130,54 & 92,46 & 91,31 \\
$\mathrm{R} 3$ & 172,08 & 110,15 & 129,77 \\
\hline Promedio & 181,31 & 127,08 & 107,85 \\
\hline
\end{tabular}




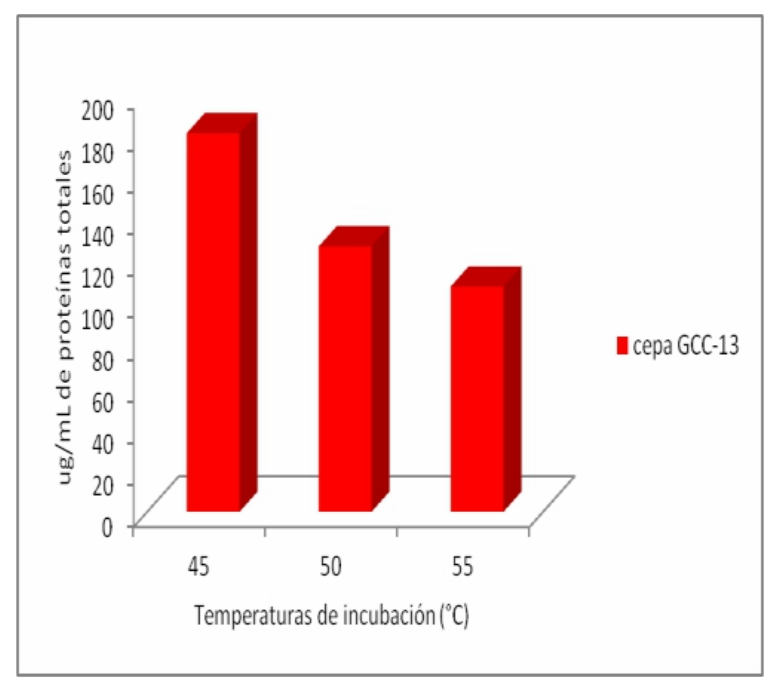

Figura 8. Representación en barras de las proteínas totales producidas por la cepa GCC-13 en sus tres repeticiones $(\mathrm{R})$ por temperatura

Tanto en la Tabla 4 como en la Figura 8 , se verifica mayor producción de proteínas totales a $45^{\circ} \mathrm{C}$ con un valor de $181,31 \mathrm{ug} / \mathrm{mL}$ por parte de la cepa GCC-13.

Actividad enzimática de las celulasas a través de la determinación de azúcares reductores en la cepa GCC-13.

Tabla 5. Azúcares reductores producidos por la cepa GCC13 en sus tres repeticiones $(R)$ por temperatura

\begin{tabular}{llll}
\hline $\begin{array}{l}\text { Repeticiones } \\
\text { del }\end{array}$ & \multicolumn{3}{c}{ Temperatura } \\
\cline { 2 - 4 } experimento & $45^{\circ} \mathrm{C}$ & $50^{\circ} \mathrm{C}$ & $55^{\circ} \mathrm{C}$ \\
\hline $\mathrm{R} 1$ & 20 & 350 & 226,67 \\
$\mathrm{R} 2$ & 33,33 & 76,67 & 146,67 \\
$\mathrm{R} 3$ & 280 & 366,67 & 96,67 \\
\hline Promedio & 111,11 & 264,45 & 156,67 \\
\hline
\end{tabular}

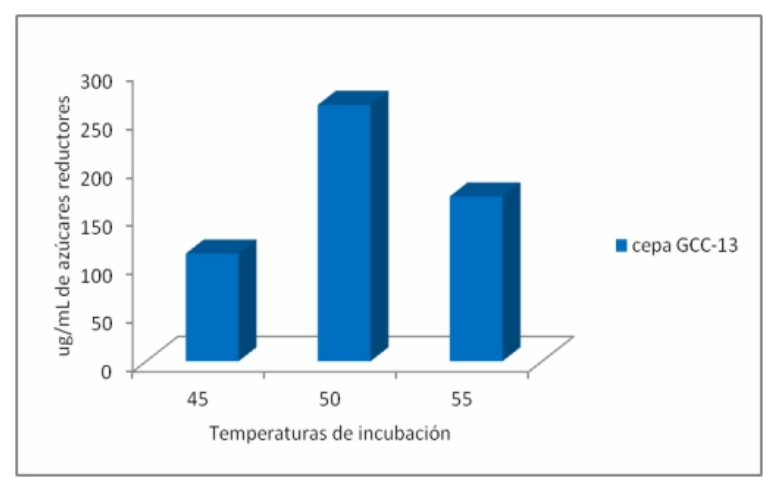

Figura 9. Representación en barras de los azúcares reductores producidos por la cepa GCC-13 en sus tres repeticiones $(\mathrm{R})$ por temperatura

\section{DISCUSIÓN}

\section{Microorganismos celulolíticos}

Los trabajos reportados por Ahmad y Baker (1987) así como por Meyer (1994) y Khalid et al. (2006) indican la capacidad del género Bacillus de degradar la celulosa. Se conoce también que Paenibacillus puede actuar sobre la celulosa y el xilano, además de crecer en ambientes aerobios de elevada temperatura y con presencia de restos vegetales, según señala también Wang et al. (2008).

\section{Capacidad enzimática de las cepas aisladas}

La mayor producción de proteínas totales (181,31ug/mL) observada en Paenibacillus sp (GCC13) a $45^{\circ} \mathrm{C}$ señala una relación inversa entre la producción de proteínas totales y la temperatura. La mayor producción de azúcares reductores $(686,67$ $\mathrm{ug} / \mathrm{mL}$ ) observada en Bacillus sp (GCB-13) a $45^{\circ} \mathrm{C}$ revela mayor capacidad celulolítica en función de la actividad enzimática de celulasas. Por reportes, en relación a las bacterias, se encontró que su mayor actividad enzimática se produjo a las 48 horas del proceso de evaluación (Viviano, 2011, Acharya y Chaudhar, 2011). Esto concuerda con lo encontrado para Bacillus sp, que presentó una mayor actividad enzimática a $45^{\circ} \mathrm{C}$ y a las 48 horas de proceso de evaluación.

\section{CONCLUSIONES}

Los microorganismos aislados de las fuentes termales de Calientes, Candarave-Tacna, corresponden a bacilos Gram positivos de los géneros Bacillus sp y Paenibacillus sp, los cuales mostraron mayor actividad enzimática a $45^{\circ} \mathrm{C}$ y $55^{\circ} \mathrm{C}$. La cepa GCB- 13 presentó mayor halo a $55^{\circ} \mathrm{C}$ correspondiente a $4,4 \mathrm{~mm}$ de diámetro de colonia y $11 \mathrm{~mm}$ de halo más colonia, en tanto que la cepa GCC-13 presentó mayor halo a $55^{\circ} \mathrm{C}$ correspondiente a $6 \mathrm{~mm}$ de diámetro de colonia y $11,9 \mathrm{~mm}$ de diámetro de colonia más halo.

La relación entre la producción de proteínas totales y azúcares reductores de la cepa GCB-13 es la siguiente: a $45^{\circ} \mathrm{C}$ por cada $\mathrm{ug} / \mathrm{mL}$ de proteínas totales, se produce $4,58 \mathrm{ug} / \mathrm{mL}$ de azúcares reductores; a $50^{\circ} \mathrm{C}$ por cada $\mathrm{ug} / \mathrm{mL}$ de proteínas totales, se genera $3,24 \mathrm{ug} / \mathrm{mL}$ de azúcares reductores; a $55^{\circ} \mathrm{C}$ por cada $\mathrm{ug} / \mathrm{mL}$ de proteínas totales se produce $3,58 \mathrm{ug} / \mathrm{mL}$ de azúcares reductores. Por otro lado, en lo que respecta a la cepa GCC- 13 , a $45^{\circ} \mathrm{C}$ por cada $\mathrm{ug} / \mathrm{mL}$ de proteínas totales, se desarrolla $3,58 \mathrm{ug} / \mathrm{mL}$ de azúcares reductores; a $50^{\circ} \mathrm{C}$ se produce por cada ug $/ \mathrm{mL}$ de proteínas totales, $4,56 \mathrm{ug} / \mathrm{mL}$ de azúcares reductores; y a $55^{\circ} \mathrm{C}$ por cada $\mathrm{ug} / \mathrm{mL}$ de proteínas totales, se genera $4,25 \mathrm{ug} / \mathrm{mL}$ de azúcares reductores.

En síntesis, se determinó que la producción de proteínas totales de la cepa GCB-13 no presenta 
diferencias significativas a temperaturas de incubación de 45,50 y $55^{\circ} \mathrm{C}$; como sí ocurre en la producción de azúcares reductores, donde se determinó una mayor productividad a $45^{\circ} \mathrm{C}$ y $55^{\circ} \mathrm{C}$. En cuanto a la cepa GCC-13, no se encontró diferencias significativas en la producción de proteínas totales y azúcares reductores a tres temperaturas de incubación; por lo que se concluye que existe un rango más amplio respecto a la productividad de la enzima celulolítica tanto como a la de azúcares reductores.

\section{AGRADECIMIENTOS}

Al proyecto Biotecnología de Microorganismos Termófilos de la región Tacna-Perú como Plataforma Base de Producción de Enzimas Termofílicas para Aplicaciones Industriales, financiado por el Consejo Nacional de Ciencia, Tecnología e Innovación Tecnológica (CONCYTEC), nuestra gratitud por financiar parcialmente el desarrollo del presente proyecto.

\section{REFERENCIAS BIBLIOGRÁFICAS}

Acharya, S., Chaudhary, A. (2011). Effect of nutritional and environmental factors on cellulase activity by thermophilic bacteria isolated from hot spring. J Sci Ind Res, pp. 142- 148.

Ahmad J.S. y Baker R. (1987). Competitive saprophytic ability and cellulolytic activity of rhizosphere-competent mutants of Trichoderma harzianum. Phytopathology 77, pp. 358-362.

Atlas, R.M. y Bartha, R. (2005). Ecología Microbiana y Microbiología Ambiental. $4^{\mathrm{a}}$ edición. Pearson Educación, S.A. Madrid, España, pp. 398-400.

Beguin, P. y Aubert, J.-P. (1994). The biological degradation of cellulose. FEMS Microbiol Revs 13,pp. 25-58.

Bradford, M. (1976). A rapid and sensitive method for the quantification of microGram quantites of protein utilizing the principle de protein dye binding. Analytical Biochem.72, pp. 248-254.

Cruz, N., Castellanos, D. y Argüello, H. (2009). Degradación de celulosa y xilano por microorganismos aislados de dos tipos de compost de residuos agrícolas en la sabana de Bogotá. Rev. Colomb. Cienc. Hortíc. 3(2), pp. 237-249.

Cuervo, L., Folch, J.L. y Quiroz, R.E. (2009). Lignocelulosa como fuente de azúcares para la producción de etanol. Biotecnología. 13(3), pp. 11-25.

Gaitán, D. (2007). Aislamiento y evaluación de microorganismos celulolíticos a partir de residuos vegetales frescos y en compost generados en un cultivo de crisantemo (Dendranthema grandiflora). Pontificia
Universidad Javeriana. Facultad de Ciencias. Carrera de Microbiología Industrial.

García, C. (2003). Técnicas de análisis de parámetros bioquímicos en suelos. España: Ediciones Mundi Prensa.

Gómez, S., \& Tibayde, M. (2009). Caracterización microbiológica del proceso de compostaje a partir de residuos azucareros microbial. Agronomía Tropical, 59(3), pp. 309-316.

Gray, K.A., Zhao, L. y Emptage, M. (2006). Bioethanol. Curr. Opin. Chem. Biol. 10(2), pp. 141-146.

Hernández, A., García, E. y Rodríguez, H. (1999). Celulosomas: sistemas multienzimáticos. Rev. Soc. Quim. Mex.43(3-4), pp.137-142.

Hreggvidsson, G.O., Kaiste, E., Holst, O., Eggrtsson, G., Paldottir, A. y Kristjansson, J.K. (1996). An extremely thermo stable cellulase from the thermophilic eubacterium Rhodothermus marines. Appl. Environ. Microbiol. 62(8), pp. 3047-3049.

Khalid, M., Yang W.J., Kishwar N., Rajput Z.I. \& Arijo A.G. (2006). Study of cellulolytic soil fungi and two nova species and new medium. J Zhejiang Univ Sci B 7(6), pp. 459-466.

Kumar, S., Singh, S.D., Mishra, I.M. \& Adhikari, D.K. (2009). Recent advances in production of bioetanol from lignocellulosic biomass. Chem. Eng. Technol.32(4), pp. 517-526.

Liang, Y., Yesuf, J. \& Feng, Z. (2010). Toward plant cell wall degradation under thermophilic condition: a unique microbial community developed originally from swine waste. Appl Biochem Biotechnol.161(1-8), pp. 147-56.

Liang, Y., Yesuf, J., Schmitt, S., Bender, K. \& Bozzol, J. (2009). Study of cellulases from a newly isolated thermophilic and cellulolytic Brevibacillus sp. strain JXL. J Ind Microbiol Biotechnol. 36(7), pp. 961-70.

Lynd, L. R., Weimer P. J., van Zyl W. H. \& Pretorius I. S. (2002). Microbial cellulose utilization: fundamentals and biotechnology. Microb. Mol. Biol. Rev. 66, pp. 506-577.

Maki, M. L., Broere, M., Leung, K.T. \& Qin, W. (2011). Characterization of some efficient cellulase producing bacteria isolated from paper mill sludges and organic fertilizers. Int. J. Biochem. Mol. Biol. 2(2), pp. 146-154.

Martínez, A.T., Speranza, M., Ruiz-Dueñas, F.J., Ferreira, P., Camarero, S., Guillén, F., Martínez, M.J., Gutiérrez, A. \& Del Río, J.C. (2005). Biodegradation of lignocellulosics: microbial, chemical and enzymatic aspects of fungal attack of lignin. Inter. Microbiol. 8(3), pp. 195-204.

Martínez-Anaya, C., Belcazar-López, E., DantanGonzález, E. y Folch-Mallol, J.L. (2008). Celulasas fúngicas: Aspectos biológicos y aplicaciones en la industria energética. Rev. Latinoam. Microbiol. 50(3-4), pp.119-131.

Mejía, T., Mújica, F., González, A. y Ortega, J. (2002). 
Proteínas con afinidad a celulosa: una herramienta en biotecnología: Avance y Perspectiva. Pp. 267-271.

Meyer, O. (1994). Functional groups of microorganisms, En: Schulze E.D. and Mooney H.A. Biodiversity and ecosystem function. Springer, New York, pp. 67-93.

Miller, G. (1959). Use of Dinitrosalisyc Acid Reagent for determination of reducing sugar. Analytical chemistry. 31, pp. 426-428.

Murashima, K., A. \& Kosugi, R. H. (2002). Synergistic effects on crystalline cellulose degradation between cellulosomal cellulases from Clostridium cellulovorans. J. Bacteriol. 184, pp. 5088-5095.

Oliveira, L.A., Porto, L.F.A. \& Tambourgi, E.B. (2006). Production of xylanase and protease by Penicillum janthinellum CRC $87 \mathrm{M}-115$ from different agricultura wastes. Bioresource Technol.97(6), pp. 862-867.

Ovando-Chacón, S.L. y Wahszewski, K.N. (2005). Preparativos de celulasas comerciales y aplicaciones en procesos extractivos. Universidady Ciencia. 21(42), pp. 111-120.

Pérez, J., Muñoz-Dorado, J., de la Rubia, T. \& Martínez, J. (2002). Biodegradation and biological treatments of cellulose, hemicellulose and lignin: an overview. Int. Microbiol. 5(2), pp.53-63.

Rodríguez, F. (2005). Biotecnología Ambiental. Madrid: Editorial Tébar.

Sheble, A.S. \& El-diwany, A.I. (2007). Isolation and identification of new cellulases producing thermophilic bacteria from an Egyptian hot spring and some properties of the crude enzyme. Aust. J. Basic and Appl. Sci. 1(4), pp. 473-478.

Sissons, S.H., Sharrock, K.R., Daniel, R.M. \& Morgan, H.W. (1987). Isolation of cellulolytic anaerobic extreme thermophiles from New Zealand thermal sites. Appl. Environ. Microbiol. 53(4), pp. 832-838

Terry-Brown, C.J., Bermúdez, R.C., Rodríguez, S. y Fernández, M. (2004). Selección de un inóculo para la degradación anaerobia de la pulpa de café. Tecnología Química. 24(2), pp. 64-71.

Thomson, J. A. (1993). Molecular biology of xylan degradation-FEMS Microbiol. Rev. 104, pp. 65-82.

Viviano, F., Medina, L., Ramos, N., Amaíz, L. y Valbuena, O. (2011). Degradación de celulasa por bacterias de aguas termales de las trincheras, Venezuela. Rev. Latinoam Biotecnol Amb Algal 2(1), pp. 18-29.

Wang, C. M., Shyu, C. L., Ho, S. P \& Chiou, S. H. (2008). Characterization of a novel thermophilic, cellulose-degrading bacterium Paenibacillus sp. strain B39. Lett Appl Microbiol. 47(1), pp. 46-53.

Yin, L.J., Huang, P.S., Lin, H.H. (2010). Isolation of cellulase producing bacteria and characterization of the cellulase from the isolated bacterium Cellulomonas sp YJ5. J. Agri. Food. Chem. 58(17), pp. 9833-9837. 